\title{
ANALISIS PERANAN AUDITOR INTERNAL TERHADAP FUNGSI PEMASARAN(PROMOSI) PADA HOTEL TRANSIT SYARIAH MEDAN
}

\author{
Siti Aisyah \\ Fakultas Ekonomi dan Bisnis, Program Studi Akuntansi, \\ Univesitas Potensi Utama,Jl. K.L.Yos Sudarso, \\ Tj.Mulia,Medan Deli, Kota Medan-20241 Telp (061)6640525 \\ Email:aisyah10041993@gmail.com
}

\begin{abstract}
ABSTRAK
Tujuan penelitian ini adalah untuk mengetahui peranan auditor internal dalam fungsi pemasaran pada hotel transit syariah Medan. Jenis penelitian ini adalah penelitian kualitatid deskriptif, yang menggunakan data primer dan data sekunder sebagai acuan dalam menganalisis. Teknik penelitian yang digunakan adalah observasi dan wawancara. Peranan seorang auditor internal bagi sebuah perusahaan sangatlah penting dalam menganalisis,menemukan, dan mengevaluasi masalah dari berbagai aspek yang nantinya laporan audit tersebut diharapkan mampu menjadi acuan dalam pengambilan keputusan. Begitu juga dengan yang terjadi pada hotel transit syariah Medan sekarang ini. Kurangnya jumlah pengunjung disebabkan oleh kurang gesitnya dan kreatifnya promosi atau pemasaran yang dilakukan pihak hotel. Hal ini seharusnya menjadi bahan evaluasi bagi audtior ketika mengaudit sistem promosi perusahaan. Karena diharapkan dengan ditemukannya banyak kekurangan pada bagian promosi inilah, perusahaan dapat melakukan perbaikan guna meningkatkan jumlah pengunjung dan laba. Karena seperti yang diketahui selama covid-19 berlangsung, hotel transit syariah mengalami jumlah penurunan pengunjung yang drastis, dan salah satu faktor penyebabnya adalah karena kurangnya promosi.
\end{abstract}

Kata Kunci: Auditor Internal, Fungsi Pemasaran (promosi)

\begin{abstract}
The purpose of this study was to determine the role of internal auditors in the marketing function of the Medan sharia transit hotel. This type of research is descriptive qualitative research, which uses primary data and secondary data as a reference in analyzing. The research technique used is observation and interviews. The role of an internal auditor for a company is very important in analyzing, finding, and evaluating problems from various aspects which later on the audit report is expected to be able to become a reference in decision making. Likewise with what is happening at the Medan sharia transit hotel today. The lack of visitors is caused by the lack of agility and creative promotion or marketing carried out by the hotel. This should be an evaluation material for the auditor when auditing the company's promotion system. Because it is hoped that with the discovery of many shortcomings in this promotion section, the company can make improvements to increase the number of visitors and profits. Because as is known during the Covid-19 pandemic, sharia transit hotels experienced a drastic decrease in the number of visitors, and one of the contributing factors was the lack of promotion.
\end{abstract}

Keywords: Internal Auditor, Marketing Function (promotion) 


\section{PENDAHULUAN}

Para pebisnis dan pengusaha yang menjalankan usaha di era Covid-19 pada nyatanya sangatlah mengalami banyak masalah dan kendala. Masyarakat yang mulai kehilangan pekerjaan, pemberhentian kerja oleh perusahaan, penutupan bisnis usaha oleh pemerintah demi mengurangi mobilitas tentulah sangat mempengaruhi segala aspek kehidupan masyarakat. Terutama aspek ekonomi, baik dari ekonomi kelas atas, menegah, dan bawah, semua terkena dampaknya. Ini jugalah yang diraskaan oleh para pengusaha yang bergerak di bidang hotel syariah. Masyarakat yang memiliki keuangan terbatas tentulah lebih mengedepankan kebutuhan primer daripada untuk menginap dihotel. Namun bisnis para pengusaha ini harus tetap berjalan demi keberlangsungan usahanya, dan yang pastinya demi bisa memberi gaji para karyawannya. Disinilah para pengusaha harus kreatif dan memutar otaknya, bagaimana caranya agar usahanya tetap berjalan walaupun di era covid-19 ini. Berdasarkan wawancara dan pengamatan peneliti, hotel transit syariah yang terletak di Medan sangatlah mengalami penurunan pengunjung semenjak awal covidhingga sekarang. Ditambah lagi cara promosi atau pemasaran yang masih sangat kurang kreatif dan minim sekali dilakukan. Pihak hotel masih mempromosikan hotelnya hanya dengan menggunakan Spanduk didepan hotel saja. Disinilah peran auditot internal seharusnya mengaudit dan menganalisis bagian promosi maupun sumber daya manusianya. Karena ternyata pihak hotel melakukan audit internal per 3 bulan sekali. Harus ada evaluasi dan perbaikan kinerja yang disampaikan auditor internal agar pihak hotel mampu mencapai tujuan usahanya, yaitu memperoleh laba. Selain itu minimnya sumber daya manusia yang dimiliki pihak hotel juga menjadi penyebab menurunnya pendapatan hotel. Sebab sumber daya manusia yang terbatas menyebabkan pihak hotel melakukan rangkap jabatan kepada beberapa karyawan, yang sebenarnya tidak kompeten dibidangnya. Di zaman yang serba digital sekarang, tentulah kita harus mampu mengolaborasi antara teknologi dan usaha kita. Pihak hotel bisa saja menggunakan instagram yang menarik untuk media promosi. Karena seperti yang kita ketahui bahwa sekarang kaun millenial sangatlah aktif menggunakan instagram dalam mencari informasi dan mengunjungi tempat - tempat menarik. Hal inilah yang menarik perhatian peneliti untuk melakukan penelitian di hotel transit syariah.

\section{LANDASAN TEORI}

\subsection{Pengertian auditor internal}

Auditor internal merupakan fungsi yang sangat penting dan riskan bagi sebuah perusahaan. Dengan adanya auditor internal, diharapkan perusahaan mampu mengadakan perbaikan dan pengevaluasian demi meningkatkan kinerja perusahaan. Ebrikut beberap apengertian auditor internal menurut para ahli :

1. Menurut Hery (2016) audit internal adalah sebuah fungsi penilaian, pengevaluasian, dan pengawasan pada sebuah perusahaan dengan tujuan adanya perbaikan pada setiap fungsi dan sistem perusahaan.

2. Adapun menurut arief (20160 audit internal merupakan suatu alat di dalam perusahaan yang diharapkan mampu menignkatkan efektivitas seluruh pihak yang terdapat di dalam perusahaan, guna mencapai tujuan perusahaan.

3. Zamzami (2016) mengatakan bahwa auditor internal adalah fungsi dari perusahaan yang bersifat objektif dan independen guna meningkatkan kegiatan operasional perusahaan 
Dari beberapa pernyataan para ahli diatas, dapat disimpulkan bahwa auditor internal merupakan sebuah fungsi yang sangat penting bagi perusahaan, yang tugasnya adalah untuk menilai dan mengevaluasi serta menberikan saran demi meningkatkan keefektifitasan operasional perusahaan dalam rangka memperolehlaba.

\subsection{Indikator pengukur Auditor internal}

Dalam melaksanakan tugasnya, tentulah seorang auditor internal harus kompeten dibidangnya guna menghasilkan laporan audit yang berkualitas dan berguna untuk para pemakai informasi. Menurut sudarmanto( 2014:53) ada ebberapa kompetensi yang harus dimiliki oleh seorang auditor internal ,yaitu:

1. Motives (motivasi), jadi seorang auditor harus konsisten menyelaraskan antara motivasi dan tindakan yang akan dilakukannya guna mencapai tujuan audit.

2. Traits (sifat), seorang auditor harus memiliki sifa-sifat yang diatur dalam kode etik audit dalam melaksanakan prosedur auditnya.

3. Self-concept merupakan nilai,sikap dan citra yang dimiliki oleh seorang auditor

4. Knowledge (pengetahun), ialah pengetahuan atau berbagai informasi yang harus dimiliki oleh seorang auditor dalam bidangnya.

5. Skill (kemampuan), merupakan kemampuan seorang auditor dalam melaksanakan tugasnya.

\subsection{Pengertian Pemasaran}

pemasaran adalah serangkaian proses menganalisis, merencanakan, melaksanakan dan mengawasi dimana tujuannya adalah untuk mencapai target perusahaan secara efektif dan efisien. Pemasaran menjadi salah salah satu faktor yang penting sangat dalam memajukan sebuh perusahaan yang bergerak dalam bidang barang maupun jasa. Aktivitas pemasaran merupakan aktivitas menawarkan produk dan menjual produk, tapi bila ditinjau lebih lanjut ternyata makna pemasaran bukan hanya sekedar menawarkan atau menjual produk saja, melainkan aktivitas yang menganalisa dan mengevaluasi tentang kebutuhan dan keinginan konsumen agar para konsumen tertarik dengan produk atau jasa yang kita tawarkan. Adapun penegrtian pemasaran menurut beberapa ahli:

1. Menurut Tjiptono (2016:3), pemasaran adalah serangkaian aktivitas atau institusi yang berupaya untuk menciptakan, mengkomunikasikan, menyapaikan, dan menawarkan produk atau jasa yang dimiliki perusahaan kepada klien, mitra, atau masyarkat

2. Menurut Abdullah dan Tantri (2012:2), pemasaran merupakan sistem yang dirancang untuk menentukan harga dan mempromosikan atau menawarkan barang kepada para konsumen guna memenuhi keinginan para konsumen

\subsection{Fungsi Pemasaran}

Pemasaran memiliki beberapa fungsi, adapun fungsi pemasaran yang dikemukakan menurut Sudaryono (2016:50) sebagai berikut:

1. Fungsi Pertukaran :Dengan adanya pemasaran, pembeli dapat membeli produk dari produsen. Baik dengan menukar uang dengan produk maupun menukar produk dengan produk (barter) untuk dipakai sendiri atau untuk dijual kembali. Pertukaran merupakan salah satu dari empat cara orang mendapatkan suatu produk.

2. Fungsi Distribusi Fisik: Distribusi fisik suatu produk dilakukan dengan mengangkut serta menyimpan produk. Produk diangkut dari produsen mendekati konsumen yang membutuhkan dengan banyak cara, baik melalui air, darat, udara, dan sebagainya. Penyimpanan produk mengedepankan upaya 
menjaga pasokan produk agar tidak kekurangan saat dibutuhkan.

3. Fungsi Perantara : Untuk menyampaikan produk dari tangan produsen ke tangan konsumen dapat dilakukan melalui perantara pemasaran yang menghubungkan aktivitas pertukaran dengan distirbusi fisik. Aktivitas fungsi perantara antara lain pengurangan risiko, pembiayaan, pencarian informasi serta standarisasi dan penggolongan (klarifikasi) produk.

\subsection{Indikator Pengukur Strategi atau fungsi Pemasaran}

Menurut Corey dalam Tjiptono (2010:7), ada 5 elemen yang masuk kedalam strategi pemasaran yang saling berkait, kelima elemen tersebut adalah:

1. Pemilihan pasar, yaitu memilih pasar yang akan dilayani yang dimulai dengan melakukan segmentasi pasar dan kemudian memilih sasaran yang paling memungkinkan untuk dilayani atau dugapai oleh perusahaan.

2. Perencanaan produk, meliputi produk barang atau jasa apa yang diproduksi dan ditawarkan, kualitasnya, keefesienannya, serta kebermanfaatan dan keunikannya sehingga masyarkat atau konsumen tertarik.

3. Penetapan harga, yaitu menentukan harga yang relevan dan relatif bersaing sehingga dapat mencerminkan nilai kuantitatif dari produk kepada pelanggan.

4. Sistem distribusi, yaitu saluran wholesale dan retail yang dilalui produk hingga mencapai konsumen akhir yang membeli dan menggunakannya.

5. Komuniksi pemasaran (promosi), yang meliputi periklanan, personal selling, dan public relation yang kreatif, menarik dan mampu menjangkau konsumen dari berbagai kalangan.

\section{METODOLOGIPENELITIAN}

\subsection{Jenis Data}

Adapun jenis data yang diperoleh peneulis dalam penelitian ini adalah sebagai berikut :

1. Data Primer

Merupakan data yang diperoleh secara langsung oleh penulis dari sumber datanya. Data primer disebut juga sebagai data asli atau data baru terkini. Untuk mendapatkan data primer, penulis harus mengumpulkannya secara langsung. Adapun sumber data primer dar penelitian ini adalah auditor internal hotel transit syariah yang berjumlah 1 orang dan manager bagian pemasaran berjumlah 1 orang

2. Data Sekunder

Data yang penulis peroleh penulis dari berbagai sumber yang telah ada. Data sekunder dapatdiperoleh dari berbagai sumber seperti buku, jurnal, informasi perusahaan maupun internet.

\subsection{Metode Pengumpulan Data}

Dalam kegiatan penelitian ini, data dan informasi dikumpulkan dengan menggunakanbeberapa teknik pengumpulan data, yaitu:

\section{a. Observasi}

Observasi yang dilakukan oleh penulis adalah dengan mengamati dan menganalisis permasalahan yang terjadi di hotel transit syariah Medan , penyebabnya, dan berusaha menemukan solusinya. 
b. Wawancara (interview)

Pengumpulan data yang digunakan oleh penulis untuk mendapatkan informasi dengan melakukan tanya jawab secara lisan dan tatap muka dengan auditor internal dan manager bagian pemasaran hotel transit syariah Medan.

\subsection{Metode Analisis Data}

Metode analisis yang digunakan oleh penulis adalah metode deskriptif, yaitu dengan cara menentukan, mengumpulkan data, mengklasifikasikan dan kemudian membandingkan dengan teori-teori, lalu diambil suatu kesimpulan dan selanjutnya diberikan saran.

\subsection{Waktu Penelitian}

Dalam penelitian ini untuk melengkapi bahan penulisan skripsi dilaksanakan mulai dari bulan April 2021 sampai dengan bulan Mei 2021.

\section{HASIL DAN PEMBAHASAN}

Pada awalnya hotel ini bernama Hotel Transit yang dipemrakarsai oleh Elly Elisabeth Kangean, dengan adanya proses jual beli antara Elly Elisabeth Kangean dengan H. Nazaruddin Dekgam, SH. Pada tahun 2012 maka management hotel diambil alih oleh H. Nazaruddin Dekgam, SH. Dibawah badan usaha CV. Grand Transit Hotel dan nama hotel diganti menjadi Grand Transit Hotel. Untuk meningkatkan pelayanan kepada tamu maka CV. Grand Transit Hotel berencana melakukan renovasi dan penambahan lantai gedung dari berlantai 3 menjadi lantai 4 sehingga hal ini akan menambah jumlah kamar dari 27 menjadi 42 kamar.

Menurut Peraturan Pemerintah No. 27 tahun 2012 tentang Izin Lingkungan maka adanya perubahan kegiatan baik perubahan nama, kapasitas kegiatan maka terhadap kegiatan tersebut diwajibkan menyusun UKL dan UPL baru jika perubahan yang akan terjadi tidak dikategorikan kegiatan wajib AMDAL.

Sehubungan dengan hal tersebut, maka CV. Grand Transit Hotel menyusun UKL dan UPL terhadap kegiatan ini. Penyusunan UKL dan UPL Grand Transit Hotel mengacu kepada Peraturan Menteri Lingkungan Hidup No. 16 tahun 2012 tentang pedoman penyusunan dokumen lingkungan hidup. UKL dan UPL akan menjadi panduan dan pedoman bagi pemrakarsa dalam melakukan pengelolaan dan pemantauan lingkungan hidup selanjutnya sehingga tercapai sasaran pembangunan di Indonesia yaitu Pembangunan berkelanjutan dan berwawasan lingkungan.

Berdasarkan hasil observasi, wawancara, dan analisis yang peneliti lakukan, maka banyak sekali ditemukan faktor-faktor penyebab menurunnya pengunjung yang menginap dihotel transit syariah di tahun 2021. Berikut pointpoint penting dari sisi promosi atau fungsi pemasaran:

1. Selain segi ekonomi, ternyata ketidak updatean pihak hotel dalam mempromosikan hotelnya menjadi dalah satu penyebab banyak masyarakat yang tidak mengetahui keberadaan hotel tersebut dan menurunnya pengunjung yang menginap dihotel tersebut. 
2. Promosi yang msih bersifat brosur dan spanduk sangatlah tidak efesien dan menjangkau seluruh pelosok, terutama masyarakat kota medan. Apalagi dimasa pandemi covid-19 dimana masyarakat sangat mengurangi mobilitas diluar rumah, sehingga mengakses segala informasi dari rumah secara online. Sudah seharusnya pihak hotel memberikan arahan atau pelatihan kepada para karyawan yang bertugas dibagian pemasaran untuk lebih kreatif dan berinovasi dalam mempromosikan hotel transit syariah ini.

3. Tidak memiliki media promosi online, baik web, instagram atau yang lainnya. Inilah yang menjadi salah satu masalah banyak masyarakat yang ingin menginap, tidak mengetahui keberadaan hotel transit syariah. Padahal berdasarkan pengamatan peneliti dilapangan, harga yang ditawarkan untuk menginap 1 malam di room yang standar sangatlah murah dan terjangkau, yaitu sebesar Rp. 100.000

4. Fasilitas yang lengkap, kerapian, kebersihan, dan keunikan juga merupakan salah satu media promosi tersendiri yang harus diperhatikan dan akan menjadi daya tarik untuk membuat konsumen kembali mengunjungi hotel tersebut. Karena masih ada beberapa yang harus diperhatikan dan memerlukan perawtan, seperti cat gedung hotel yang mulai pudar sehingga terlihat kusam dan lusuh. Beberapa sudut ruangan yang masih belum terawat dan kamar yang harus selalu wangi dan jauh dari bau apek. Tentunya para konsumen yang hidup di zaman millenial sekarang tidak luput dari yang namanya media sosial. Mereka akan sangat mengetahui dengan cepat informasi dari internet dan mencari tahu hotel - hotel sebagai tempat penginapan ketika berkunjung ke Medan.

Di sisi lain ada juga ditemukan beberapa masalah dari pihak auditor internalnya, yang ternyata memiliki banyak sekali kekurangan dari bebrapa aspek, yaitu :

1. auditor internalnya yang ternyata tidak memiliki background ilmu auditing, dan hanya sebatas lulusan Sarjana Akuntansi saja. Hal ini menyebabkanauditor internal kurang memahami cara mengaudit perusahan hampir dibeberapa aspek, baik keuangan, operasional dan pemasarannya. Seperti yang diketahui, hasil laporan audit sehatusnya bersifat handal dan dapat dipertanggungjawabkan. Sebab, laporan audit inilah yang nantinya akan menjadi acuan bagi pemilik hotel, manager, dan pihak lain yang membutuhkan informasi tersebut, guna mengambil keputusan dan melihat perkembangan laba hotel, pengunjung, serta aspek lainnya.

2. Ditemukan juga bahwasannya, pihak auditor internal belum mendapatkan pelatihan guna meningkatkan kemampuannya, sehingga ilmu dan kemampuan yang dimilki sangat minim sekali dan terbatas.

3. Kurangnya kemampuan auditor dalam memberikan saran terhadap temuan permasalahan terutama dibagian promsi atau pemasaran kepada pemilik usaha guna dilakukannya peningkatan dan perubahan strategi promosi, menyebabkan pemilik usaha atau manager tidak melakukan perbaikan atau perubahan.

4. Terakhir ditemukannya perangkapan jabatan dibeberapa karyawan, dikarenakan pengurangan karyawan masa pandemi. Sehingga menyebabkan kinerja karawan tidak maksimal, termasuk auditor internal yang juga ternyata bertugas menjadi bagian administrasi

Berikut struktur organisasi dari hotel tansit syariah Medan: 

a. Manager(semua divisi)
: Bambang Yusisto
b. Supervisor (semua divisi)
: Surya Darma
c. Adminitrastion(auditor internal) : Nafasul Nizam
d. Reception Annisa Sofyati Sa'bani Damanik
e. Roomboy
f. Security
g. Laundry(kitchen)
:Firmansyah, Alex Sandro Marbun,
: Hendra Gunawan, Ilham Munanda
: Dendi Aldino
: Syamri Fahanum

\section{Strukłur Organisasi CV. GRAND TRANSIT HOTEL.}

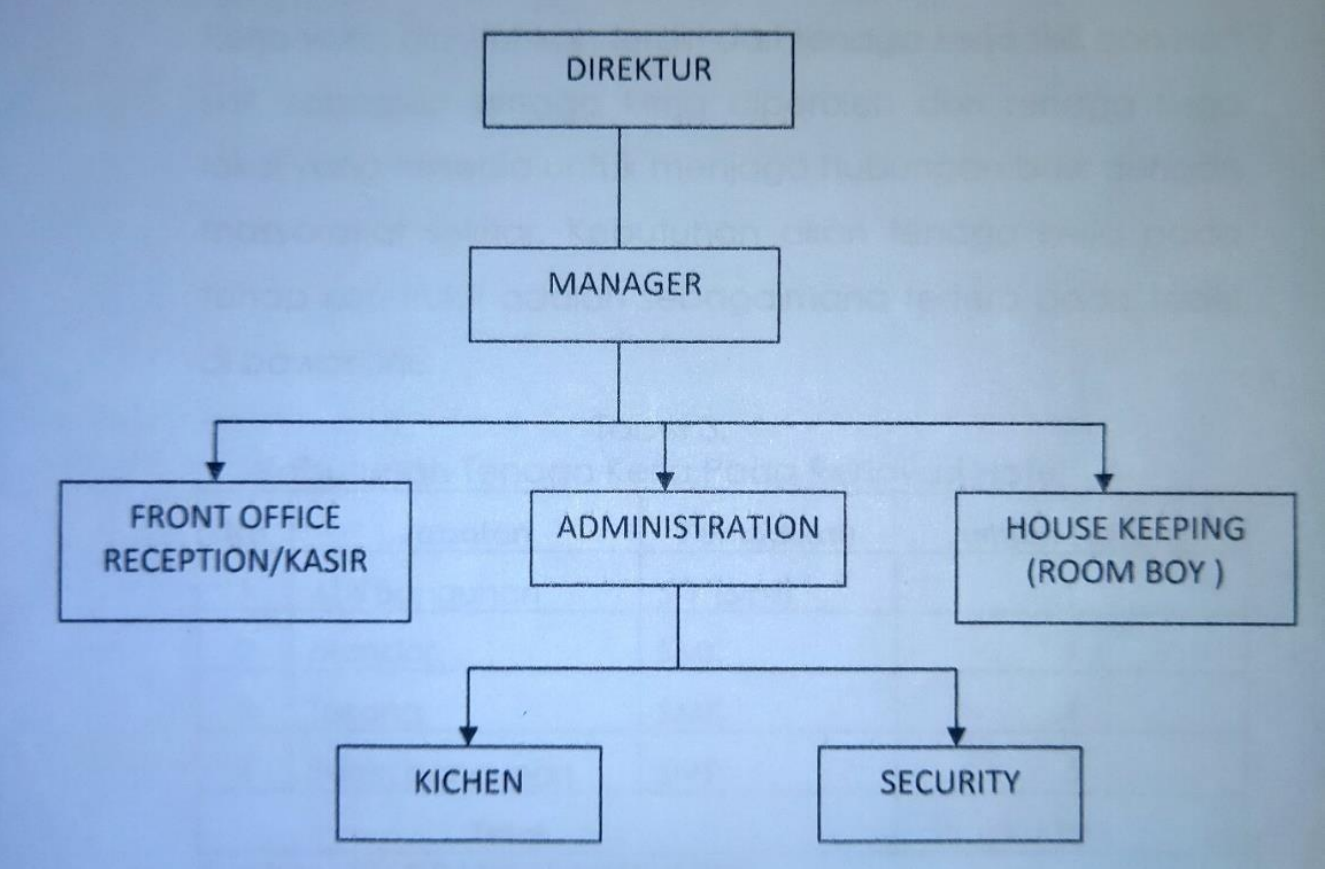

Gambar 1. Struktur Organisasi

Dari penjabaran mengenai struktur organisasi diatas, dapat dilihat banyaknya rangkap jabatan yang terjadi pada satu orang. Hal ini membuat para karyawan tidak bekerja dengan fokus pada bidangnya, karena harus kesana kemari mengurus pekerjaan yang lain. Sama halnya seorang administrasi yang merangkap sebagai auditor yang sebenarnya sangatlah tidak etis.

Kegiatan audit bukanlah hal sepel, sebab dari hasil auditlah pihak hotel dapat mengetahui masalah apa saja yang terjadi diperusahaannya. Baik itu masalah keuangan yang dilihat dari laporan audit keuangan, masalah sumber daya manusianya yang dilihat dari audit SDM, masalah operasional yang didalamnya termaasuk masalah fungsi pemasaran. Oleh sebab itu, hal inilah yang harus diperbaiki pihak hotel demi keberlangsungan usahanya, apalagi dimasa covid-19 ini. Harus mampu mengolaborasi antara penggunaan akses digital dengan kegiatan promosi agar menjangkau seluruh indonesia, serta kinerja auditor yang harus lebih baik lagi guna memberikan hasil evaluasi yang lebih baik dan bermanfaat. 


\section{KESIMPULAN}

\section{Kesimpulan}

Adapun kesimpulan dari hasil penelitian yang berjudul" Analisis Peranan Auditor Internal Terhadap Fungsi Pemasaran(Promosi) Pada Hotel Transit Syariah Medan"adalah sebagai berikut:

1. Kurangnya kreatifitas pihak hotel dalam melakukan promosi, yaitu dengan menggunakan media digital seperti web, instagram ataupun situs online lainnya

2. Para karyawan yang kurang kompeten dibidangnya, termasuk auditor internalnya yang masih minim dengan ilmu audit.

3. Terdapat rangkap jabatan pada beberapa karyawan yang mengakibatkan hasil kerja yang kurang efektifnya dan tidak sesuai harapan.

\section{Saran} berikut :

Untuk mengakhiri penulisan ini, penulis akan memberikan beberapa saransebagai

1. Bagi pihak hotel diharapkan mampu beradaptasi dengan kemajuan zaman. Menggunakan akses digital sebagai media promosi yang lebih mudah, murah dan cepat, serta mampu menjangkau segala aspek dan seluruh pelosok indonesia.

2. Menghilangkan rangkap jabatan dan memebrikan pelatihan bagi para auditornya jika memang para karyawan bukanlah lulusan seorang auditor.

3. Bagi penelitian selanjutnya, disarankan untuk menambah variabel penelitian atau merubah varibel penelitian .

\section{DAFTAR PUSTAKA}

[1] Abdullah, Thamrin dan Francis Tantri. 2012. Manajemen Pemasaran Cetakan Pertama. Jakarta : PT. Raja Grafindon Persada.

[2] Hery. 2016. Auditing dan Asurans, Jakarta: Grasindo

[3] Hery. 2016. Akuntansi Dasar 1 \& 2. Jakarta: Grasindo.

[4] Sudarmanto., 2014. Kinerja Dan Pengembangan Kompetensi Sdm. Cetakan Kedua. Yogyakarta : Pustaka Pelajar

[5] Sudaryono. 2016. Manajemen Pemasaran Teori Dan Implementasi. Yogyakarta: ANDI

[6] Zamzami, Faiz., Ihda Arifin Faiz, dan Mukhlis. (2016). Audit Internal Konsep dan Praktik. Yogyakarta: Gadjah Mada University Press

[7] Tjiptono, Fandy. 2010, Strategi Pemasaran, Edisi 2, Andi Offset, Yogyakarta. 
Prima. Andi Offset, Yogyakarta.

[9] - 2015. Strategi Pemasaran, Edisi 4.Andi Offset, Yogyakarta. 